\title{
Clinical Study \\ Effect of Salt-Bromide-Iodine Thermal Water Inhalation on Functional and Biochemical Lung Parameters
}

\author{
Massimo Corradi, ${ }^{1}$ Giuseppina Folesani, ${ }^{2}$ Petra Gergelova, ${ }^{3}$ Matteo Goldoni, ${ }^{1,2}$ \\ Silvana Pinelli, ${ }^{1}$ Gianfranco Gainotti, ${ }^{4}$ Giuseppe De Palma, ${ }^{5}$ and Antonio Mutti ${ }^{1}$ \\ ${ }^{1}$ Laboratory of Industrial Toxicology, Department of Clinical Medicine, Nephrology and Health Sciences, University of Parma, \\ Via Gramsci 14, 43126 Parma, Italy \\ ${ }^{2}$ Italian Workers' Compensation Authority (INAIL), Research Center at the University of Parma, Via Gramsci 14, 43126 Parma, Italy \\ ${ }^{3}$ Department of Public Health, Faculty of Health Care and Social Work, Trnava University, 91700 Trnava, Slovakia \\ ${ }^{4}$ Terme of Monticelli, Via alle Terme, 43022 Monticelli Terme, Parma, Italy \\ ${ }^{5}$ Laboratory of Industrial Hygiene and Toxicology, University Hospital of Brescia, Piazzale Spedali Civili 1, 25123 Brescia, Italy
}

Correspondence should be addressed to Massimo Corradi, massimo.corradi@unipr.it

Received 10 April 2012; Accepted 10 May 2012

Academic Editors: B. Antus and A. Miyazato

Copyright (C) 2012 Massimo Corradi et al. This is an open access article distributed under the Creative Commons Attribution License, which permits unrestricted use, distribution, and reproduction in any medium, provided the original work is properly cited.

\begin{abstract}
Background. Inhalation of thermal water has been used empirically in the treatment of chronic diseases of upper and lower respiratory tract. This study investigates biomarkers of effect in exhaled breath (nitric oxide (NO)) and in exhaled breath condensate (EBC) (hydrogen peroxide $\left(\mathrm{H}_{2} \mathrm{O}_{2}\right)$, anions, toxic heavy metals of tobacco smoke) for patients with lung diseases inhaling salt-bromide-iodine thermal water. Methods. This study enrolled two groups of patients, twenty with alveolar pulmonary diseases-pneumoconiosis - twenty-two with bronchial diseases. Patients received 12 days inhalation treatment with thermal water in Terme of Monticelli (Parma), Italy. Results. No statistically significant differences were found for NO at different flow rates in both groups of patients before and after thermal water inhalation. Also in EBC no statistically significant differences were present for $\mathrm{H}_{2} \mathrm{O}_{2}$ concentrations, toxic heavy metals concentrations, and anion concentrations before and after treatment. Nitrates in EBC were found to be significantly higher in patients before inhalation than in controls as well as in patients after inhalation versus controls. Conclusions. This study contributes to better quantify functional and biochemical changes in airways before and after thermal water treatment.
\end{abstract}

\section{Introduction}

The treatment of diseases with thermal water belongs to the oldest medical therapies. Waters and their components were used as therapeutic agents from the nineteenth century to the present day especially for lung diseases. The most frequently used therapies based on mineral waters were drinking, bath, and inhalation cures. The positive influence of these cures on the recovery of the patients was attributed to the physicochemical properties of the water. Particulary, some studies show that sulphurous thermal water inhalation has mucolitic, antioxidant, and antielastase activity [1] that may help to control airway inflammation at the upper alveolar or lower bronchial level $[2,3]$. The possible benefit of thermal sulphurous water inhalation could be attributed to the presence of hydrogen sulphide $\left(\mathrm{H}_{2} \mathrm{~S}\right)$. In the past, hydrogen sulphide was considered only a toxic gas. Recent studies indicate that it is also produced at significant amounts $(50 \mu \mathrm{M})$ in most tissues and exerts many physiological effects suggesting its potential role as a regulatory mediator such as monoxide oxide (CO) or nitric oxide (NO) [4]. Moreover, inhaling treatments can be done with salt-bromide-iodine thermal waters of natural springs. Many scientists think that particular composition of this thermal water plays a useful anti-inflammatory and sedative purifying action on the mucous membranes of the respiratory apparatus: aerosol tiny particels are vaporized and inhaled by the subjects, pass through respiratory tract, giving relief to nose, throat, 
bronchus, lungs, and larynx. In the literature there are only few works that study the effect of inhalation of salt-bromideiodine thermal water on airway inflammation in patients with lung diseases such as chronic obstructive pulmonary disease (COPD) $[5,6]$. Moreover, despite its widespread use, much uncertainty exists about the indications and therapeutic mechanisms of thermal water inhalations in the treatment of respiratory diseases. Particularly, $\mathrm{H}_{2} \mathrm{~S}$ is a strong reducing agent, that is present in salt-bromide-iodine water at lower concentration compared to sulphurous thermal, therefore, it has been suggested that some of its benefit effects may be mediated by protection of protein thiol groups from oxidation. Additional mechanism through which $\mathrm{H}_{2} \mathrm{~S}$ and other salts may exert antioxidant effect involves stimulation of cysteine transport to the cells and enhancement of glutathione synthesis [7]. Molecules bearing SH groups, such as gluthatione (GSH), play a fundamental role in the defensive system of human airways: GSH concentrations (200-400 $\mu \mathrm{M})$ in the epithelial lining fluid (ELF) of the lungs are approximately 100 times higher than that of plasma (2$4 \mu \mathrm{M})$. Lung extracellular ELF is rich in the antioxidant GSH, which detoxifies oxidants, free radicals, and electrophilic compounds such as ions of heavy metals contained in cigarette smoke: lead $(\mathrm{Pb})$, cadmium $(\mathrm{Cd})$, and cobalt $(\mathrm{Co})$ [8]. The aim of this study was to investigate and to quantify the effects of salt-bromide-iodine thermal water inhalation on lung function parameters and on biomarkers detected in biological matrices, collected noninvasively (exhaled breath and exhaled breath condensate (EBC)). The assessment of inflammatory in exhaled air was evaluated with fractional exhaled nitric oxide (FENO) $[9,10]$. In order to evaluate the effect of thermal treatment on EBC anions concentration and to compare it with EBC sample controls, we quantified six anions (formate, chloride, nitrite, nitrate, sulphate, and oxalate) before and after inhalation of thermal salt-bromideiodine thermal water in patients with respiratory diseases.

\section{Materials and Methods}

2.1. Study Design. The design of the present study was focused on two groups of patients with pneumoconiosis and with bronchial diseases inhaling salt-bromide-iodine thermal water in Terme of Monticelli (Parma), Italy. This thermal water is classified as medium-mineral and contains bromide, iodide, hydrogen sulphide, and sulphates, springs forth at temperature of $13^{\circ} \mathrm{C}$, and is used in treatment of different respiratory diseases. The aerosol was administrated daily for 12 consecutive days. Spirometry and exhaled breath collection was performed before and after 12 days of treatment. Subjects completed also a questionnaire covering respiratory symptoms, smoking habits, and information about environmental and occupational exposures.

The protocol was approved by the Ethic Committee of the University Hospital of Parma, and patients signed an informed consent.

2.2. Subjects. This study enrolled two groups, twenty (20) patients with alveolar pulmonary diseases-pneumoconiosis-(15 men and 5 women, aged 54-84) and twenty two (22) patients with bronchial diseases (11 men and 11 women, aged 41-82). Patients received 12 days inhalation treatment with salt-bromide-iodine water in Terme of Monticelli (Parma), Italy. The pneumopathology of each subject was ascertained according to standard diagnostic tests with the recommendations of the American Thoracic Society/European Respiratory Society (ATS/ERS) [11]. All 20 pneumoconiosis were recognized as occupational diseases by former exposure to asbestos or crystalline silica dust and granted by the Italian Workers' Compensation Authority. In order to evaluate the effect of thermal water inhalation on metallic elements present in the airways, the subgroup of 21 patients with relevant smoking history (at least 10 pack/years) was earmarked. Smoking status was assessed in terms of self-reported smoking history (cigarette/day, pack/years). Ex-smokers were defined as those patients who stopped smoking for at least six months. The exclusion criteria for both groups were acute respiratory illness in the three weeks preceding the study and the recent use of medications (antihistamines, bronchodilators). Table 1 shows the main characteristics of the two groups. 17 healthy subjects (4 men and 13 women, range aged 24-53) not exposed to thermal water were recruited as controls for quantification of anions in EBC samples.

2.3. Spirometry. Forced vital capacity (FVC), forced expiratory volume (FEV1), FEV1/FVC ratio, peak expiratory flow rate (PEFR), and forced expiratory flow $25-75 \%$ (FEF $25-75 \%$ ) were measured using a KOKO spirometer (Sensormedics Italia Srl, Milan, Italy), and the best of three values were expressed as a percentage of the predicted normal value. Measurements were obtained and evaluated in accordance with the recommendations of the ATS/ERS [11].

2.4. Exhaled NO (eNO) Measurements. eNO was measured by portable device composed with electrochemical sensor (HypAir FENO, Sensormedics, Milan, Italy). The analyzer was calibrated by the manufacturer with range from 100 to $1000 \mathrm{ppb}$, linearity error $<0.5 \%$, and reproducibility of $\pm 2.5 \mathrm{ppb}$ adapted for online recording of $\mathrm{NO}$ concentration in exhaled breath. HypAir FENO is enabled to measure the eNO at multiple exhaled flow rates and calculates bronchial and alveolar eNO concentration. It is possible to calculate also three flow-dependent $\mathrm{NO}$ exchange parameters: airway tissue nitric oxide concentration $\left(\mathrm{C}_{\mathrm{aw}, \mathrm{NO}}\right)$, alveolar nitric oxide concentration $\left(\mathrm{C}_{\mathrm{A}, \mathrm{NO}}\right)$, and airway transfer factor (or diffusing capacity) for nitric oxide $\left(\mathrm{D}_{\mathrm{aw}, \mathrm{NO}}=\mathrm{C}_{\mathrm{aw}, \mathrm{NO}}-\right.$ $\mathrm{C}_{\mathrm{A}, \mathrm{NO}}$ ). We quantified the fractional nitric oxide concentration at different flow rates, $50 \mathrm{~mL} / \mathrm{s}\left(\mathrm{FENO}_{50}\right), 100 \mathrm{~mL} / \mathrm{s}$ $\left(\mathrm{FENO}_{100}\right), 150 \mathrm{~mL} / \mathrm{s}\left(\mathrm{FENO}_{150}\right), 350 \mathrm{~mL} / \mathrm{s}\left(\mathrm{FENO}_{350}\right)$, the $\mathrm{C}_{\mathrm{A}, \mathrm{NO}}$, and the maximum total airway nitric oxide flux $\left(\mathrm{J}^{\prime}{ }_{\mathrm{aw}, \mathrm{NO}}\right)$ from $\mathrm{D}_{\mathrm{aw}, \mathrm{NO}}$. Subjects abstained from food and caffeine intake for $2 \mathrm{~h}$, smoking for $6 \mathrm{~h}$, and alcohol for $12 \mathrm{~h}$ before the test. All exhaled NO measurements were performed according to current ATS/ERS guidelines [12].

2.5. EBC Biomarkers. The transportable unit TURBODECCS condenser (Medivac, Parma, Italy) was used for EBC collection. Patients were asked to breath tidally through 
TABLE 1: Characteristic of the groups.

\begin{tabular}{|c|c|c|c|c|c|}
\hline Subjects & Gender & Age & BMI & Smokers/Ex-smokers $(N)$ & Pack/years (PY) \\
\hline Total $(N=42)$ & $M=26 ; F=16$ & $70.8 \pm 9.3$ & $28.2 \pm 4.5$ & $7 / 18$ & $23.5(14.3-39.5)$ \\
\hline \multicolumn{6}{|l|}{ Alveolar diseases $(N=20)$} \\
\hline (i) Silicosis $(N=12)$ & $M=10 ; F=2$ & $76.3 \pm 5.0$ & $27.2 \pm 3.5$ & $0 / 8$ & $17(5.8-37.3)$ \\
\hline (ii) Asbestosis $(N=6)$ & $\mathrm{M}=3 ; \mathrm{F}=3$ & $65.5 \pm 9.9$ & $26.6 \pm 4.2$ & $2 / 1$ & $24(1.4-68)$ \\
\hline (iii) Silicoasbestosis $(N=2)$ & $\mathrm{M}=2 ; \mathrm{F}=0$ & $69.5 \pm 0.7$ & $28.9 \pm 0.7$ & $0 / 1$ & - \\
\hline \multicolumn{6}{|l|}{ Bronchial diseases $(N=22)$} \\
\hline (i) Chronic bronchitis $(N=15)$ & $M=7 ; F=8$ & $68.3 \pm 9.3$ & $30.3 \pm 7.2$ & $3 / 6$ & $22.5(14.5-70.3)$ \\
\hline (ii) Asthma $(N=7)$ & $\mathrm{M}=4 ; \mathrm{F}=3$ & $66.1 \pm 11.6$ & $27.8 \pm 2.8$ & $2 / 3$ & $23.4(17.1-50.5)$ \\
\hline Smokers or ex smokers with PY $>10(N=21)$ & $\mathrm{M}=17 ; \mathrm{F}=4$ & $70.4 \pm 11.5$ & $28 \pm 3.3$ & $7 / 14$ & $25(17-48.8)$ \\
\hline
\end{tabular}

Data presented as mean \pm SD; SD: standard deviation or median (IQR); IQR: interquartile range.

the mouthpiece for 15 minutes through a two-way nonrebreathing valve by which inspiratory and expiratory air is separated and saliva is trapped. The temperature of the condenser was set at $-5^{\circ} \mathrm{C}$, respecting all of the recommended practical standards and anticontamination principles for EBC collection published by ATS/ERS [13]. 1-2 mL of EBC samples were stored immediately at $-80^{\circ} \mathrm{C}$ and kept frozen until analysis.

2.5.1. $\mathrm{H}_{2} \mathrm{O}_{2} \cdot \mathrm{H}_{2} \mathrm{O}_{2}$ in $\mathrm{EBC}$ was measured using a commercial kit (Amplex Red Hydrogen Peroxide/Peroxidase assay kit, Molecular Probes, Eugene, OR, USA). Briefly, $50 \mu \mathrm{L}$ of EBC was mixed with $50 \mu \mathrm{L}$ of a solution containing 0.2 $\mathrm{U} / \mathrm{mL}$ horseradish peroxidase (HRP), $100 \mu \mathrm{M}$ 10-acetyl3,7-dihydroxyphenoxazine (Amplex Red reagent) and was incubated for $30 \mathrm{~min}$ at room temperature, protected from light. $\mathrm{H}_{2} \mathrm{O}_{2}$ reacts with the Amplex Red reagent (1:1 stoichiometry) in the presence of HRP to produce highly fluorescent resorufin. The amount of resorufin, as a measure of the amount of $\mathrm{H}_{2} \mathrm{O}_{2}$, was determined spectrofluorimetrically using a Cary Eclipse fluorescence spectrophotometer (Varian Inc., Palo Alto, CA, USA). $\mathrm{H}_{2} \mathrm{O}_{2}$ calibration curve was composed with seven concentration levels (range 0$5.0 \mu \mathrm{M})$.

2.5.2. Metals. EBC samples were sent, on dry ice, to the Laboratory of Industrial Hygiene and Toxicology, University Hospital of Brescia (Italy). The laboratory is certified for analysis of metallic elements. EBC samples underwent inductively coupled plasma-mass spectrometry (ICP-MS) analysis on a Perkin Elmer ELAN DRC II instrument (Perkin Elmer, Sciex, Canada) using an analytical technique for total quantification with external calibration and reference material. For each sample, two runs were performed (two replicates each), one with dynamic reaction cell (DRC) and one without DRC. We determined concentrations of the following elements: arsenic $(\mathrm{As})$, barium $(\mathrm{Ba})$, cadmium $(\mathrm{Cd})$, calcium $(\mathrm{Ca})$, cobalt $(\mathrm{Co})$, chromium $(\mathrm{Cr})$, copper $(\mathrm{Cu})$, iron $(\mathrm{Fe})$, mercury $(\mathrm{Hg})$, manganese $(\mathrm{Mn})$, molybdenum $(\mathrm{Mo})$, nickel $(\mathrm{Ni})$, lead $(\mathrm{Pb})$, selenium $(\mathrm{Se})$, strontium $(\mathrm{Sr})$, tin $(\mathrm{Sn})$, vanadium $(\mathrm{V})$, and zinc $(\mathrm{Zn}) ; \mathrm{Cr}$ and $\mathrm{Fe}$ were determined by DRC using $\mathrm{NH}_{3}$ at a flow of $0.6 \mathrm{~mL} / \mathrm{min}$. The method accuracy was determined in natural water standard reference materials (NIST 1640 from the National Institute of Standard and Technology, Gaithersburg, MD 20899-1070). The coefficients of variation (CV) ranged from $4 \%$ to $8 \%$ among series and from $6 \%$ to $12 \%$ between series. The instrument was calibrated using standard solution at a concentration of $10 \mu \mathrm{g} / \mathrm{L}$ (Multielement ICP-MS Calibration Standard 3, Matrix per Volume: $5 \% \mathrm{HNO}_{3}$ per $100 \mathrm{~mL}$, Perkin Elmer Plus) including $\mathrm{Al}, \mathrm{As}, \mathrm{Ba}, \mathrm{Be}, \mathrm{Bi}, \mathrm{Ca}, \mathrm{Cd}$, $\mathrm{Co}, \mathrm{Cr}, \mathrm{Cs}, \mathrm{Cu}, \mathrm{Fe}, \mathrm{Ga}$, In, K, Li, Mg, Mn, Ni, Pb, Rb, Se, $\mathrm{Na}, \mathrm{Ag}, \mathrm{Sr}, \mathrm{Ti}, \mathrm{V}, \mathrm{U}$. The limits of detection (LOD) were determined on the basis of $3 \mathrm{SD}$ of the background signal and the following values (as $\mu \mathrm{g} / \mathrm{L}$ ) were obtained: 0.001 for As and V; 0.002 for $\mathrm{Cr}, \mathrm{Mn}$, and Zn; 0.003 for Co; 0.004 for $\mathrm{Cs}, \mathrm{Cu}, \mathrm{Ni}, \mathrm{Pb}$, and $\mathrm{Sr} ; 0.005$ for $\mathrm{Ba}, \mathrm{Mo}, \mathrm{Fe}, \mathrm{Hg}$, and Sn; 0.006 for Cd; 0.05 for Se; 1.0 for Ca.

2.5.3. Anions. The quantification of anions was performed by ion exchange Dionex chromatography (ICS 2100, Dionex Corporation, Sunnyvale, CA). One hundred $\mu \mathrm{L}$ for each sample has injected manually. After separation on Dionex Ion Pack AS19 $4 \times 250 \mathrm{~mm}$ column equipped with AG19 $4 \times$ $50 \mathrm{~mm}$ precolumn at $30^{\circ} \mathrm{C}$, the anions were quantitated by conductance measurements. The temperature of conductometric cell was set at $35^{\circ} \mathrm{C}$. The eluent was generated electrolytically with potassium hydroxide. During each sample run, the eluent concentration was increased along a linear gradient of $\mathrm{KOH}$. The suppressor was Dionex ASRS 300 $4 \mathrm{~mm}$ with current of 112 milli Ampere. The eluent flow rate was $1 \mathrm{~mL} / \mathrm{min}$ in accordance with the recommendation from the column manufacturer. The noise was $1 \mathrm{nS}$. The multianalytes standard solutions were prepared daily from a Dionex stock solution. The limit of detection (LOD) for each anion was formate $15 \mathrm{ppb}$, chloride $10 \mathrm{ppb}$, nitrite $10 \mathrm{ppb}$, nitrate $10 \mathrm{ppb}$, sulphate $10 \mathrm{ppb}$, and oxalate $5 \mathrm{ppb}(\mathrm{ppb}=\mu \mathrm{g} / \mathrm{L})$.

2.6. Statistical Analysis. The data were statistically analyzed using the SPSS software v.17.0 (SPSS inc., Chicago, IL, USA) and a $P$ value $<0.05$ was always considered significant. The distributions of all the variables were tested by means of the Kolmogorov-Smirnov test: normally distributed variables are expressed as mean values $\pm \mathrm{SD}$, and not normally distributed variables as median values with the IQR (25th and 75th percentiles). Depending on the normality of variables, the 
TABLE 2: Effect of 12 days thermal treatment with salt-bromide-iodine thermal water on lung function parameters.

\begin{tabular}{|c|c|c|c|c|c|c|}
\hline \multirow{2}{*}{ Variables } & \multicolumn{3}{|c|}{ Alveolar diseases } & \multicolumn{3}{|c|}{ Bronchial diseases } \\
\hline & BT & AT & ${ }^{*} P$ value & BT & AT & ${ }^{*} P$ value \\
\hline FVC (L) & $2.6 \pm 0.8$ & $2.8 \pm 0.6$ & ns & $2.5 \pm 1.1$ & $2.7 \pm 1.0$ & ns \\
\hline $\mathrm{FEV}_{1}(\mathrm{~L})$ & $2.0 \pm 0.6$ & $2.1 \pm 0.6$ & ns & $1.7 \pm 0.8$ & $1.9 \pm 0.7$ & ns \\
\hline $\mathrm{FEV}_{1} / \mathrm{FVC}(\mathrm{L})$ & $0.73 \pm 0.08$ & $0.75 \pm 0.07$ & ns & $0.68 \pm 0.12$ & $0.69 \pm 0.1$ & ns \\
\hline PEFR (L/s) & $5.1 \pm 1.9$ & $5.4 \pm 1.9$ & ns & $4.8 \pm 1.7$ & $5.1 \pm 1.8$ & $P<0.01$ \\
\hline $\mathrm{FEF}_{25-75 \%}(\mathrm{~L})$ & $1.7 \pm 0.7$ & $1.8 \pm 0.8$ & ns & $1.2 \pm 0.7$ & $1.4 \pm 0.8$ & ns \\
\hline
\end{tabular}

Data expressed as mean \pm SD; SD: standard deviation; * Paired $t$-test; BT: before treatment; AT: after treatment; ns: not significant.

Student's $t$-test for paired samples or the Wilcoxon rank sum test was used to compare the data before and after treatment.

The EBC anion concentrations were compared before and after inhalation of thermal salt-bromide-iodine water in the group of patients with pneumopathologies and versus controls by one-way ANOVA analysis of variance with Post Bonferroni test for nitrates and by Kruskal-Wallis with postDunn's test for other anions. The bivariate linear correlations between variables were reported as Rho of Spearman $(\rho)$.

\section{Results}

Twenty patients with occupational pneumoconiosis and twenty-two with bronchial diseases (asthma and chronic bronchitis) were examined. Among 42 recruited subjects, 7 current smokers and 18 ex-smokers with PY of 23.5 (14.339.5 ) were present, and subgroup of 21 patients with relevant smoking history (at least 10 PY) and PY of 25 (17-48.8) was distinguished. In 14 subjects, the airflow obstruction as ratio between $\mathrm{FEV}_{1} / \mathrm{FVC}(<0.7)$ was found; the obstruction was present in six patients with bronchial diseases and in eight patients with alveolar diseases. Among the patients with airway obstruction, two subjects were current smokers, eight of them were ex-smokers and four patients were never smokers.

3.1. Lung Function Parameters. Table 2 shows mean values \pm SD (standard deviation) of lung function parameters before and after 12 days of thermal treatment for both groups of patients. All spirometric data have been found higher after thermal treatment compared to baseline values, but only mean PEFR value in bronchial diseases increased significantly $(4.8 \pm 1.7$ versus $5.1 \pm 1.8 ; P<0.01)$. In the group of patients with airflow obstruction $(N=14)$ (Table 3$)$, the index $\mathrm{FEV}_{1} / \mathrm{FVC}$ increased significantly compared to baseline value $(0.6 \pm 0.08$ versus $0.65 \pm 0.1 ; P<0.05)$.

3.2. FENO and Flow-Dependent NO Parameters. There were no significant differences for levels of FENO at different flow rates $(50,100,150,350)$ in both groups of patients before and after thermal salt-bromide-iodine water inhalation, as reported in Table 4. Also for maximum total airway nitric oxide flux $\left(\mathrm{J}^{\prime}{ }_{\mathrm{aw}, \mathrm{NO}}\right)$ and alveolar nitric oxide concentration $\left(\mathrm{C}_{\mathrm{A}, \mathrm{NO}}\right)$, there were no statistical difference.

3.3. $\mathrm{H}_{2} \mathrm{O}_{2}$-EBC. In the group of patients with alveolar diseases, the $\mathrm{H}_{2} \mathrm{O}_{2}$-EBC concentrations before thermal
TABLE 3: Effect of 12 days thermal treatment with salt-bromideiodine thermal water on lung function parameters in patients with airflow obstruction $\left(\mathrm{FEV}_{1} / \mathrm{FVC}<0.7\right)$.

\begin{tabular}{lccc}
\hline \multirow{2}{*}{ Variables } & \multicolumn{2}{c}{ Treatment } & $* P$ value \\
& BT & AT & \\
\hline FVC $(\mathrm{L})$ & $2.5 \pm 1.1$ & $2.6 \pm 0.9$ & ns \\
FEV $_{1}(\mathrm{~L})$ & $1.7 \pm 0.8$ & $1.7 \pm 0.7$ & ns \\
$\mathrm{FEV}_{1} / \mathrm{FVC}(\mathrm{L})$ & $0.6 \pm 0.08$ & $0.65 \pm 0.1$ & $P<0.05$ \\
$\mathrm{PEFR}_{(\mathrm{L} / \mathrm{s})}$ & $4.3 \pm 1.8$ & $4.6 \pm 1.4$ & $\mathrm{~ns}$ \\
$\mathrm{FEF}_{25-75 \%}(\mathrm{~L})$ & $0.9 \pm 0.5$ & $1.1 \pm 0.6$ & $\mathrm{~ns}$ \\
\hline
\end{tabular}

Data expressed as mean $\pm \mathrm{SD}$ (standard deviation); *Paired $t$-test; BT: before treatment; AT: after treatment; ns: not significant.

treatment were not significantly compared after inhalation (0.29 (0.19-0.58) versus 0.28 (0.09-0.9), $P=$ ns; Table 5). As well, there were no significant changes in $\mathrm{H}_{2} \mathrm{O}_{2}$-EBC concentrations after 12 days of thermal treatment in group of bronchial diseases $(0.29(0.18-0.58)$ versus $0.34(0.13-0.91)$, $P=$ ns; ns = not significant, Table 5).

3.4. EBC Metals Concentrations in Subgroup of Patients with Significant Smoking History. Concentrations of metals quantified before and after treatment in EBC smokers and ex smokers with significant smoking history $(\mathrm{PY}>10)$ are reported in Table 6. All metals concentrations in EBC have not been significantly modified after thermal treatment compared to baseline values.

3.5. EBC Anions. The concentrations of anions in patients before and after inhalation of salt-bromide-iodine thermal water versus controls are reported in Table 7 . There was no statistical difference before and after thermal treatment for each anion. Regarding the EBC ionic composition, the nitrate concentrations were found to be significantly higher in patients before inhalation than in controls (1169.5 \pm 510.8 versus $256.3 \pm 171.2, P<0.001)$ as well as in patients after inhalation versus controls (1417.7 \pm 375.0 versus $256.3 \pm 171.2, P<0.001)$, Figure 1 . The contrary opposite behaviour was observed for sulphate, where the sulphate anion concentrations have been found significantly lower as compared to controls, both before (10.0 (10.0-27.9) versus (66.9 (24.6-117.9), $P<0.001)$ and after treatment $(10.0$ (10.0-24.3) versus (66.9 (24.6-117.9), $P<0.001)$. The concentrations of anions were highly correlated one each 
TABLE 4: Effect of 12 days treatment with salt-bromide-iodine thermal water on flow-dependent $\mathrm{NO}_{\text {parameters }}\left(\mathrm{FENO}_{50}, \mathrm{FENO}_{100}\right.$, $\mathrm{FENO}_{150}, \mathrm{FENO}_{350}, \mathrm{~J}^{\prime}$ aw,NO, $\left.\mathrm{C}_{\mathrm{A}, \mathrm{NO}}\right)$.

\begin{tabular}{|c|c|c|c|c|c|c|}
\hline \multirow{2}{*}{ Variable } & \multicolumn{3}{|c|}{ Alveolar diseases } & \multicolumn{3}{|c|}{ Bronchial diseases } \\
\hline & BT & AT & ${ }^{\#} P$ value & BT & AT & ${ }^{\#} P$ value \\
\hline $\mathrm{FENO}_{50}(\mathrm{ppb})$ & $25(13.3-37.8)$ & $26(16.7-44.5)$ & ns & $24(17-52)$ & $20(17-31)$ & ns \\
\hline $\mathrm{FENO}_{100}(\mathrm{ppb})$ & $18(14-28)$ & $18.5(12-22.8)$ & ns & $17(12.5-24)$ & $16(11-26)$ & ns \\
\hline $\mathrm{FENO}_{150}(\mathrm{ppb})$ & $12(11.5-23.5)$ & $11.5(9.7-23.5)$ & ns & $15.5(10-22)$ & $12.5(10.5-18.5)$ & ns \\
\hline $\mathrm{FENO}_{350}(\mathrm{ppb})$ & $10(6.5-10.5)$ & $9(5.5-12.8)$ & ns & ND & ND & ND \\
\hline $\mathrm{J}_{\mathrm{aw}, \mathrm{NO}}^{\prime}(\mathrm{nL} / \mathrm{min})$ & $54.8(35.7-112)$ & $65(37.8-92.2)$ & ns & $54.4(35.8-80.6)$ & $33.5(24.0-73.8)$ & ns \\
\hline $\mathrm{C}_{\mathrm{A}, \mathrm{NO}}(\mathrm{ppb})$ & $6.6(3.1-12.2)$ & $6.2(4-9.6)$ & ns & $7.4(3.4-19.6)$ & $9.4(5-15.6)$ & ns \\
\hline
\end{tabular}

Data expressed as median IQR; IQR: interquartile range; ${ }^{\#}$ Wilcoxon rank-sum test; BT: before treatment; AT: after treatment; FENO $_{50}$ : fractional nitric oxide concentration at flow rate of $50 \mathrm{~mL} / \mathrm{s} ; \mathrm{FENO}_{100}$ : fractional nitric oxide concentration at flow rate of $100 \mathrm{~mL} / \mathrm{s} ; \mathrm{FENO}_{150}$ : fractional nitric oxide concentration at flow rate of $150 \mathrm{~mL} / \mathrm{s} ; \mathrm{FENO}_{350}$ : fractional nitric oxide concentration at flow rate of $350 \mathrm{~mL} / \mathrm{s} ; \mathrm{J}^{\prime}$ aw,NO: maximum total airway nitric oxide flux; $\mathrm{C}_{\mathrm{A}, \mathrm{NO}}$ : alveolar nitric oxide concentration; ND: not determined; ns: not significant.

TABLE 5: Effect of 12 days treatment with salt-bromide-iodine thermal water on $\mathrm{H}_{2} \mathrm{O}_{2}$-EBC concentrations.

\begin{tabular}{lcccccc}
\hline Variable & \multicolumn{3}{c}{ Alveolar } & \multicolumn{3}{c}{ Bronchial } \\
& BT & AT & \# $P$ value & BT & AT & \# $P$ value \\
\hline $\mathrm{H}_{2} \mathrm{O}_{2}(\mu \mathrm{M})$ & $0.29(0.19-0.58)$ & $0.28(0.09-0.9)$ & ns & $0.29(0.18-0.58)$ & $0.34(0.13-0.91)$ & ns \\
\hline
\end{tabular}

Data expressed as median (IQR); IQR: interquartile range; "Wilcoxon rank sum test; BT: before treatment; AT: after treatment; ns: not significant.

TABLE 6: Effect of 12 days treatment with salt-bromide-iodine thermal water on EBC metals concentrations.

\begin{tabular}{|c|c|c|c|}
\hline Metals & BT $(\mathrm{mg} / \mathrm{L})$ & AT $(\mathrm{mg} / \mathrm{L})$ & $P$ value \\
\hline$\overline{\mathrm{Al}}$ & $1.36(0.73-2.2)$ & $1.4(1.1-2.3)$ & ${ }^{\#} \mathrm{~ns}$ \\
\hline Mn & $0.38(0.28-0.69)$ & $0.5(0.32-1.0)$ & ${ }^{\#} \mathrm{~ns}$ \\
\hline Co & $0.02(0.006-0.06)$ & $0.02(0.006-0.1)$ & ${ }^{\#} \mathrm{~ns}$ \\
\hline $\mathrm{Sr}$ & $0.56 \pm 0.09$ & $0.57 \pm 0.06$ & *ns \\
\hline $\mathrm{Ba}$ & $0.32 \pm 0.08$ & $0.33 \pm 0.06$ & $*^{*} \mathrm{~ns}$ \\
\hline $\mathrm{Ca}$ & $249(38.5-394)$ & $270(67-348)$ & ${ }^{\#} \mathrm{~ns}$ \\
\hline $\mathrm{Pb}$ & $0.043 \pm 0.01$ & $0.058 \pm 0.01$ & ${ }^{*} \mathrm{~ns}$ \\
\hline I & $0.21 \pm 0.07$ & $0.3 \pm 0.1$ & $*^{*} \mathrm{~ns}$ \\
\hline $\mathrm{Cu}$ & $1.24 \pm 0.2$ & $1.25 \pm 0.3$ & *ns \\
\hline $\mathrm{Si}$ & $50(28.8-69.8)$ & $32(15-62)$ & ${ }^{\#} \mathrm{~ns}$ \\
\hline $\mathrm{Fe}$ & $2.5(1.2-7.2)$ & $3.1(1.5-6.3)$ & ${ }^{\#} \mathrm{~ns}$ \\
\hline $\mathrm{Cr}$ & $1.2 \pm 0.4$ & $1.5 \pm 0.5$ & *ns \\
\hline $\mathrm{Ni}$ & $1.0(0.3-5.8)$ & $1.0(0.85-6.1)$ & $\# \mathrm{~ns}$ \\
\hline $\mathrm{Rb}$ & $0.09 \pm 0.01$ & $0.12 \pm 0.02$ & ${ }^{*}$ ns \\
\hline
\end{tabular}

Data expressed as median (IQR); IQR: interquartile range or mean $\pm \mathrm{SE}$; SE: standard error; "Wilcoxon rank sum test; *Paired $t$-test; BT: before treatment; AT: after treatment; ns: not significant.

other. There was a significant correlation between formate concentrations before inhalation with hydrogen peroxide before inhalation, $\rho=0.45, P<0.05$ (data not shown).

\section{Discussion}

The positive effect of the thermal water inhalation is generally based on the patients' subjective sense of wellbeing, whereas more difficult is to measure or quantify clinical improvements. In our study, we assessed the effects of
TABLE 7: EBC anions concentrations $(\mathrm{ppb}=\mu \mathrm{g} / \mathrm{L})$ for patients with pneumopathologies before and after inhalation of salt-bromideiodine thermal water versus controls.

\begin{tabular}{lccc}
\hline \multirow{2}{*}{ Anion } & \multicolumn{2}{c}{ Treatment } & Controls \\
& $\mathrm{BT}$ & $\mathrm{AT}$ & \\
\hline \multirow{2}{*}{ Formate } & $\mathbf{1 0 1 . 1}$ & $\mathbf{1 6 0 . 3}$ & $\mathbf{9 3 . 4}$ \\
& $(55.1-231.2)$ & $(85.6-208.0)$ & $(69.3-322.2)$ \\
Chloride & $\mathbf{1 9 3 . 3}$ & $\mathbf{2 2 7 . 4}$ & $\mathbf{1 0 1 . 6}$ \\
& $(88.1-271.8)$ & $(130.4-275.2)$ & $(53.6-188.9)$ \\
Nitrite & $\mathbf{4 7 . 1}$ & $\mathbf{4 0 . 6}$ & $\mathbf{6 7 . 5}$ \\
& $(21.1-141.7)$ & $(30.3-124.9)$ & $(21.9-156.8)$ \\
Nitrate & $\mathbf{1 1 6 9 . 5} \pm 510.8$ & $\mathbf{1 4 1 7 . 7} \pm 375.0$ & $\mathbf{2 5 6 . 3} \pm 171.2^{* * *}$ \\
Sulphate & $\mathbf{1 0 . 0}$ & $\mathbf{1 0}$ & $\varphi \mathbf{6 6 . 9} * *$ \\
& $(10.0-27.9)$ & $(10.0-24.3)$ & $(24.6-117.9)$ \\
Oxalate & $\mathbf{3 9 . 6}$ & $\mathbf{4 4 . 1}$ & $\mathbf{N D}$ \\
& $(34.3-48.7)$ & $(39.7-52.1)$ & \\
\hline
\end{tabular}

Data reported as median values (IQR); IQR: interquartile range, only for nitrate as mean values \pm SD (SD: standard deviation); ${ }^{¥}$ one-way ANOVA analysis of variance with Post Bonferroni test, $P<0.001 * * *$ both controls versus BT and controls versus AT; ${ }^{\varphi}$ Kruskal-Wallis with Dunn's post-test, $P<0.001 * * *$ both controls versus BT and controls versus AT; BT: before treatment; AT: after treatment; ND: not determined.

salt-bromide iodine thermal water inhalation on lung functions parameters and on effect biomarkers. To the best of our knowledge, this is the first study that has used FENO measurement at multiple exhaled flow rates in exhaled breath, metals, and anions quantification in EBC, in order to investigate the biochemical changes airways in patients with bronchial and alveolar pneumopathologies who receive the inhalation thermal treatment with salt-bromide-iodine water. Most of our patients, who receive thermal treatment every year, have confirmed the subjective improvement and 


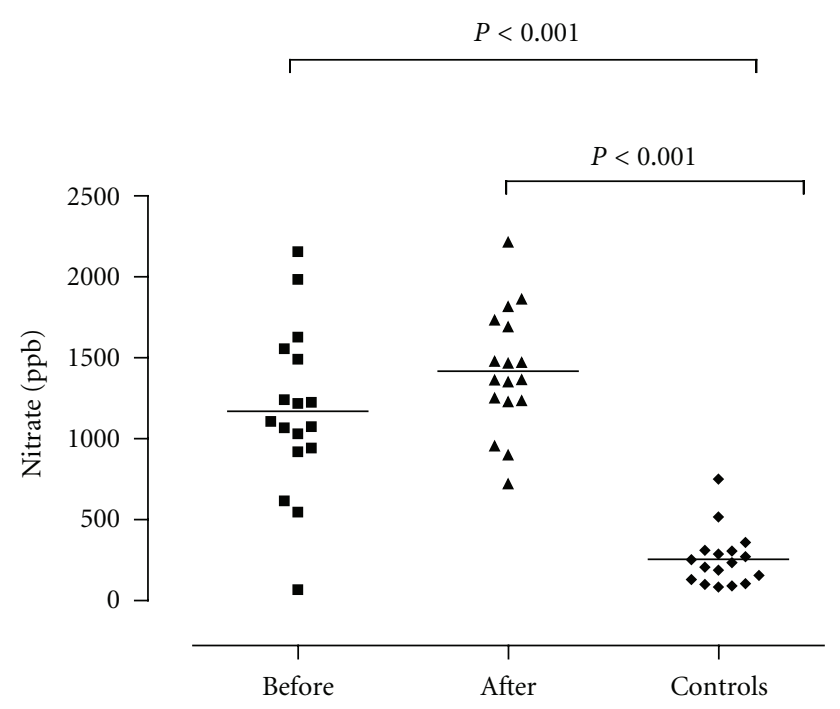

FIGURE 1: EBC nitrate concentrations for patients before and after inhalation of thermal salt-bromide-iodine water versus controls. The horizontal lines represent mean values. Statistical differences between three groups were calculated by one-way ANOVA analysis of variance with Bonferroni's post-test.

sense of "easier breathing," which usually appear in the next weeks after the end of the treatment. The PEF value in patients with bronchial diseases have increased significantly (Table 2), whereas other spirometric parameters in both bronchial and alveolar diseases have been found increased not significant after treatment. Pellegrini et al. [5] have found not significantly changes in lung function after 2 weeks of treatment with salt-bromide-iodine thermal water in COPD patients. In our study, when we analyzed the group of patients with objective airflow obstruction $\left(\mathrm{FEV}_{1} / \mathrm{FVC}<\right.$ $0.7)$, the index $\mathrm{FEV}_{1} / \mathrm{FVC}$ increased significantly after thermal treatment compared to baseline values before (Table 3 ), but the reliability of this improvement is debatable due to the small number of subjects $(N=14)$. One of the working hypothesis was that treatment with salt-bromide-iodine water was able to replace or increase GSH, reducing oxidative stress in lung disorders associated with inflammation, depletion of HS groups and production of ROS [14-16]. Recent studies have demonstrated evidences on anti-inflammatory and antioxidative effect of thermal water [1, 17-19]. Samples of exhaled breath are suitable medium to study biomarkers of pulmonary inflammation and oxidative stress, which may be sensitive endpoints for identifying biochemical changes in the airways after specific treatment [20]. FENO values after thermal treatment remained similar to those measured before inhalation (Table 4). In our study, the treatment with thermal water has not changed significantly $\mathrm{H}_{2} \mathrm{O}_{2}$ EBC concentrations (Table 5), and the working hypothesis of antioxidant effect of thermal water was not confirmed. Another working hypothesis was that thermal water was able to modify pulmonary concentration of heavy toxic metals of cigarette smoke, either through an improvement in rheological characteristics of the mucus or improving individual detoxifying capacity. It can be speculated that sulphur components can detoxify toxic elements (e.g., Hg, $\mathrm{Cd}$ and $\mathrm{Pb}$ ) making these metals soluble in water and improving their clearance. The toxic metals were detectable in EBC and have been proposed as a suitable biomarkers of exposure as a means of assessing the target tissue dose of carcinogenic and pneumotoxic substances from tobacco smoke [21]. Currently, the studies on metals in EBC after specific treatment are not available and we can only speculate about positive effect of thermal water related to supplementation of $\mathrm{SH}$ groups which should accelerate the excretion rate of the mobilized metals. Anyway, the results of our study in subjects with significant smoking history (PY > 10) have not confirmed this hypothesis. All metals analyzed in EBC before and after treatment have not shown significant differences (Table 6). Moreover, we have used ion chromatography to quantify the concentrations of six anions in EBC. This technique yields highly reproducible results with a low detection limit. Only few works in the literature have used high sensitivity ion chromatography to quantify anions composition in EBC [22]. Greenwald et al. [23] quantified EBC anions before and after exercise in adolescent healthy athletes and did not find any influence on EBC anions composition. In our study we did not find any difference in anions EBC concentrations before and after water thermal treatment in patients with bronchial and alveolar pneumopathologies. Except for nitrites and sulphates, anions EBC concentrations after treatment were higher than before, but not significant (Table 7). Greenwald et al. [24] found that EBC formate concentrations were significantly higher in the $\mathrm{EBC}$ of children with asthma than in those without asthma. For the first time, the presence of a respiratory disorder such as asthma made a difference in anions EBC composition. Also in our study we reported that patients with pneumopathologies had nitrates EBC concentrations higher compared to controls (Figure 1) and the contrary opposite behaviour was observed for sulphate concentrations (Table 7). The increased EBC nitrate levels were expected on the basis of the known enhanced production of nitric oxide oxidative products into airways of diseased subjects [13]. Recently, Malinovschi et al. [22] confirmed that EBC nitrates concentration is a biomarker significantly related to asthma control. We speculate that the reduced $\mathrm{EBC}$ sulphate concentrations in patients might be linked to a depletion of sulfhydryl- (SH-) containing molecules into airways, which may occur in patients with lung diseases [25].

\section{Conclusions}

There is no evidence that thermal water inhalation affects the inflammation and oxidative stress in the airways and modify pulmonary concentration of smoking-related biomarkers after 12 days treatment. Probably, the improvement of functional parameters and the modification of exhaled biomarkers are not detectable immediately within 12 days of treatment, and repeated follow-up examination several weeks after the end of thermal water inhalation could be important for a better understanding of possible long term effects. 


\section{Abbreviations}

\begin{tabular}{|c|c|}
\hline ATS: & American Thoracic Society \\
\hline $\mathrm{C}_{\mathrm{aw}, \mathrm{NO}}:$ & $\begin{array}{l}\text { Airway tissue nitric oxide } \\
\text { concentration }\end{array}$ \\
\hline $\mathrm{C}_{\mathrm{A}, \mathrm{NO}}$ : & $\begin{array}{l}\text { Alveolar nitric oxide } \\
\text { concentration }\end{array}$ \\
\hline $\mathrm{D}_{\mathrm{aw}, \mathrm{NO}}=\mathrm{C}_{\mathrm{aw}, \mathrm{NO}}-\mathrm{C}_{\mathrm{A}, \mathrm{NO}}$ : & Airway transfer factor \\
\hline $\mathrm{J}^{\prime}{ }_{\mathrm{aw}, \mathrm{NO}}$ : & $\begin{array}{l}\text { Maximum total airway nitric } \\
\text { oxide flux }\end{array}$ \\
\hline COPD: & $\begin{array}{l}\text { Chronic obstructive } \\
\text { pulmonary disease }\end{array}$ \\
\hline EBC: & Exhaled breath condensate \\
\hline ELF: & Epithelial lining fluid \\
\hline ERS: & European Respiratory Society \\
\hline FENO: & Fractional exhaled nitric oxide \\
\hline FEF 25-75\%: & Forced expiratory flow $25-75 \%$ \\
\hline FEV1: & Forced expiratory volume \\
\hline FVC: & Forced vital capacity \\
\hline GSH: & Gluthatione \\
\hline HRP: & Horseradish peroxidase \\
\hline $\mathrm{H}_{2} \mathrm{O}_{2}$ : & Hydrogen peroxide \\
\hline $\mathrm{H}_{2} \mathrm{~S}:$ & Hydrogen sulphide \\
\hline IQR: & Interquartile range \\
\hline LOD: & Limit of detection \\
\hline NO: & Nitric oxide \\
\hline PEFR: & Peak expiratory flow rate \\
\hline SD: & Standard deviation. \\
\hline
\end{tabular}

\section{Authors' Contribution}

M. Corradi participated in the design of the study, conducted participant visits, and analysed and interpreted the data. G. Folesani participated in the design of the study, analysed and interpreted the data, and drafted paper. P. Gergelova helped to draft the manuscript. M. Goldoni participated in the design of the study and assisted in interpretation of the data. S. Pinelli assisted with acquisition and interpretation of the data. G. Gainotti participated in the design of the study. G. De Palma participated in the design of the study and assisted with acquisition of the data. A. Mutti participated in the design of the study and helped to draft the paper. All authors have read and approved the final paper.

\section{Conflict of Interests}

The authors declared that there is no conflict of interests with any financial organization regarding the material discussed in the paper.

\section{Acknowledgments}

This study was supported by a grant from The Italian Association for Cancer Research (AIRC). Fondazione Ricerca Scientifica Termale (FoRST). The authors thank the staff of the Terme of Monticelli (Parma), Italy. Dionex Italia S.P.A. is gratefully acknowledged.

\section{References}

[1] P. C. Braga, M. Dal Sasso, M. Culici et al., "Effects of $\sim$ sulphurous water on human neutrophil elastase release," Therapeutic Advances in Respiratory Disease, vol. 4, no. 6, pp. 333340, 2010.

[2] M. Miraglia Del Giudice, F. Decimo, N. Maiello et al., "Effectiveness of ischia thermal water nasal aerosol in children with seasonal allergic rhinitis: a randomized and controlled study," International Journal of Immunopathology and Pharmacology, vol. 24, no. 4, pp. 1103-1109, 2011.

[3] A. Salami, M. Dellepiane, F. Strinati, L. Guastini, and R. Mora, "Sulphurous thermal water inhalations in the treatment of chronic rhinosinusitis," Rhinology, vol. 48, no. 1, pp. 71-76, 2010.

[4] E. Łowicka and J. Bełtowski, "Hydrogen sulfide $\left(\mathrm{H}_{2} \mathrm{~S}\right)$ - the third gas of interest for pharmacologists," Pharmacological Reports, vol. 59, no. 1, pp. 4-24, 2007.

[5] M. Pellegrini, D. Fanin, Y. Nowicki et al., "Effect of inhalation of thermal water on airway inflammation in chronic obstructive pulmonary disease," Respiratory Medicine, vol. 99, no. 6, pp. 748-754, 2005.

[6] G. Guarnieri, S. Ferrazzoni, M. C. Scarpa, A. Lalli, and P. Maestrelli, "Effects of inhalation of thermal water on exhaled breath condensate in chronic obstructive pulmonary disease," Respiration, vol. 79, no. 3, pp. 216-221, 2010.

[7] Y. Kimura and H. Kimura, "Hydrogen sulfide protects neurons from oxidative stress," FASEB Journal, vol. 18, no. 10, pp. 1165-1167, 2004.

[8] I. Rahman, "Regulation of glutathione in inflammation and chronic lung diseases," Mutation Research, vol. 579, no. 1-2, pp. 58-80, 2005.

[9] P. J. Barnes, R. A. Dweik, A. F. Gelb et al., "Exhaled nitric oxide in pulmonary diseases a comprehensive review," Chest, vol. 138, no. 3, pp. 682-692, 2010.

[10] A. Sandrini, A. R. Johnson, P. S. Thomas, and D. H. Yates, "Fractional exhaled nitric oxide concentration is increased in asbestosis and pleural plaques," Respirology, vol. 11, no. 3, pp. 325-329, 2006.

[11] M. R. Miller, J. Hankinson, V. Brusasco et al., "Standardisation of spirometry," European Respiratory Journal, vol. 26, no. 2, pp. 319-338, 2005.

[12] S. American Thoracic and S. European Respiratory, "ATS/ERS recommendations for standardized procedures for the online and offline measurement of exhaled lower respiratory nitric oxide and nasal nitric oxide, 2005," American Journal of Respiratory and Critical Care Medicine, vol. 171, no. 8, pp. 912930, 2005.

[13] I. Horváth, J. Hunt, P. J. Barnes et al., "Exhaled breath condensate: methodological recommendations and unresolved questions," European Respiratory Journal, vol. 26, no. 3, pp. 523-548, 2005.

[14] R. Hosoki, N. Matsuki, and H. Kimura, "The possible role of hydrogen sulfide as an endogenous smooth muscle relaxant in synergy with nitric oxide," Biochemical and Biophysical Research Communications, vol. 237, no. 3, pp. 527-531, 1997.

[15] B. Geng, L. Chang, C. Pan et al., "Endogenous hydrogen sulfide regulation of myocardial injury induced by isoproterenol," Biochemical and Biophysical Research Communications, vol. 318, no. 3, pp. 756-763, 2004.

[16] J. Du, Y. Hui, Y. Cheung et al., "The possible role of hydrogen sulfide as a smooth muscle cell proliferation inhibitor in rat cultured cells," Heart and Vessels, vol. 19, no. 2, pp. 75-80, 2004. 
[17] A. Staffieri, F. Marino, C. Staffieri et al., "The effects of sulfurous-arsenical-ferruginous thermal water nasal irrigation in wound healing after functional endoscopic sinus surgery for chronic rhinosinusitis: a prospective randomized study," American Journal of Otolaryngology, vol. 29, no. 4, pp. 223229, 2008.

[18] A. Salami, M. Dellepiane, B. Crippa et al., "Sulphurous water inhalations in the prophylaxis of recurrent upper respiratory tract infections," International Journal of Pediatric Otorhinolaryngology, vol. 72, no. 11, pp. 1717-1722, 2008.

[19] P. C. Braga, G. Sambataro, M. Dal Sasso, M. Culici, M. Alfieri, and G. Nappi, "Antioxidant effect of sulphurous thermal water on human neutrophil bursts: chemiluminescence evaluation," Respiration, vol. 75, no. 2, pp. 193-201, 2008.

[20] S. A. Kharitonov, L. E. Donnelly, P. Montuschi, M. Corradi, J. V. Collins, and P. J. Barnes, "Dose-dependent onset and cessation of action of inhaled budesonide on exhaled nitric oxide and symptoms in mild asthma," Thorax, vol. 57, no. 10, pp. 889-896, 2002.

[21] A. Mutti, M. Corradi, M. Goldoni, M. V. Vettori, A. Bernard, and P. Apostoli, "Exhaled metallic elements and serum pneumoproteins in asymptomatic smokers and patients with COPD or asthma," Chest, vol. 129, no. 5, pp. 1288-1297, 2006.

[22] A. Malinovschi, S. Pizzimenti, S. Sciascia, E. Heffler, I. Badiu, and G. Rolla, "Exhaled breath condensate nitrates, but not nitrites or FENO, relate to asthma control," Respiratory Medicine, vol. 105, no. 7, pp. 1007-1013, 2011.

[23] R. Greenwald, J. M. Ferdinands, and W. G. Teague, "Ionic determinants of exhaled breath condensate $\mathrm{pH}$ before and after exercise in adolescent athletes," Pediatric Pulmonology, vol. 44, no. 8, pp. 768-777, 2009.

[24] R. Greenwald, A. M. Fitzpatrick, B. Gaston, N. V. Marozkina, S. Erzurum, and W. G. Teague, "Breath formate is a marker of airway S-nitrosothiol depletion in severe asthma," PLoS ONE, vol. 5, no. 7, Article ID e11919, 2010.

[25] A. M. Sadowska, "N-Acetylcysteine mucolysis in the management of chronic obstructive pulmonary disease," Therapeutic Advances in Respiratory Disease, vol. 6, no. 3, pp. 127-135, 2012. 


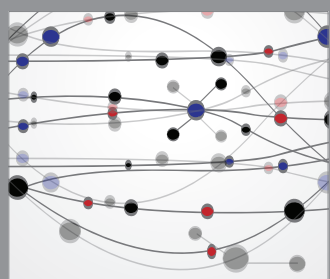

The Scientific World Journal
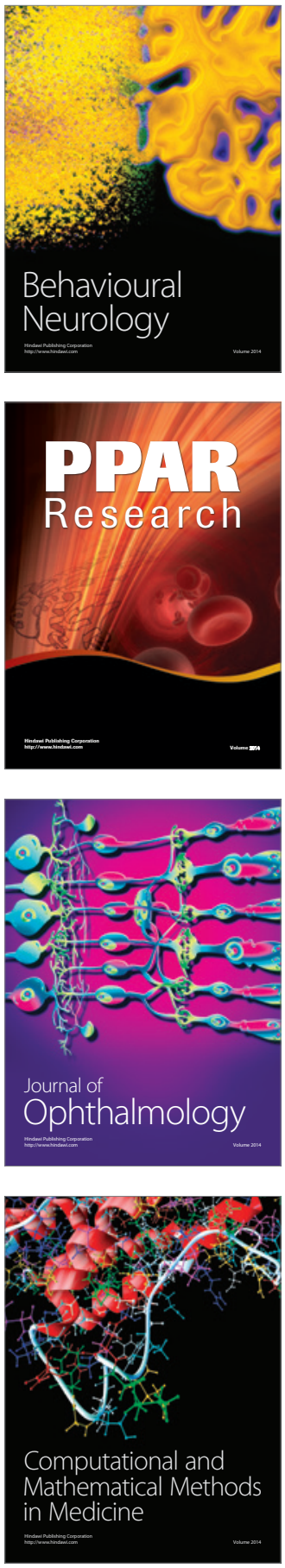

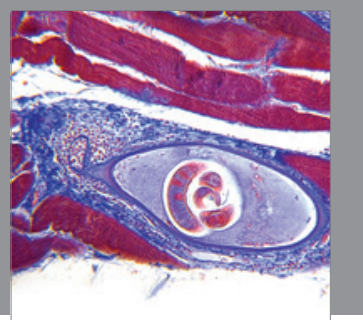

Gastroenterology

Research and Practice
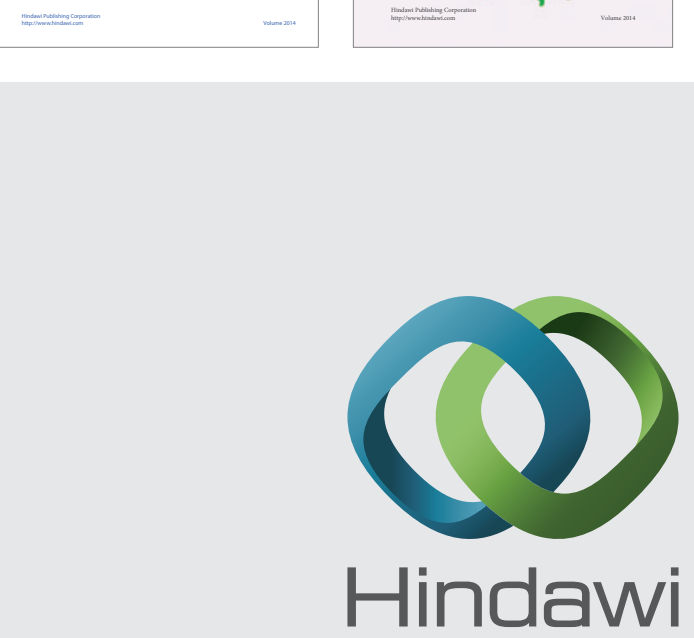

Submit your manuscripts at

http://www.hindawi.com
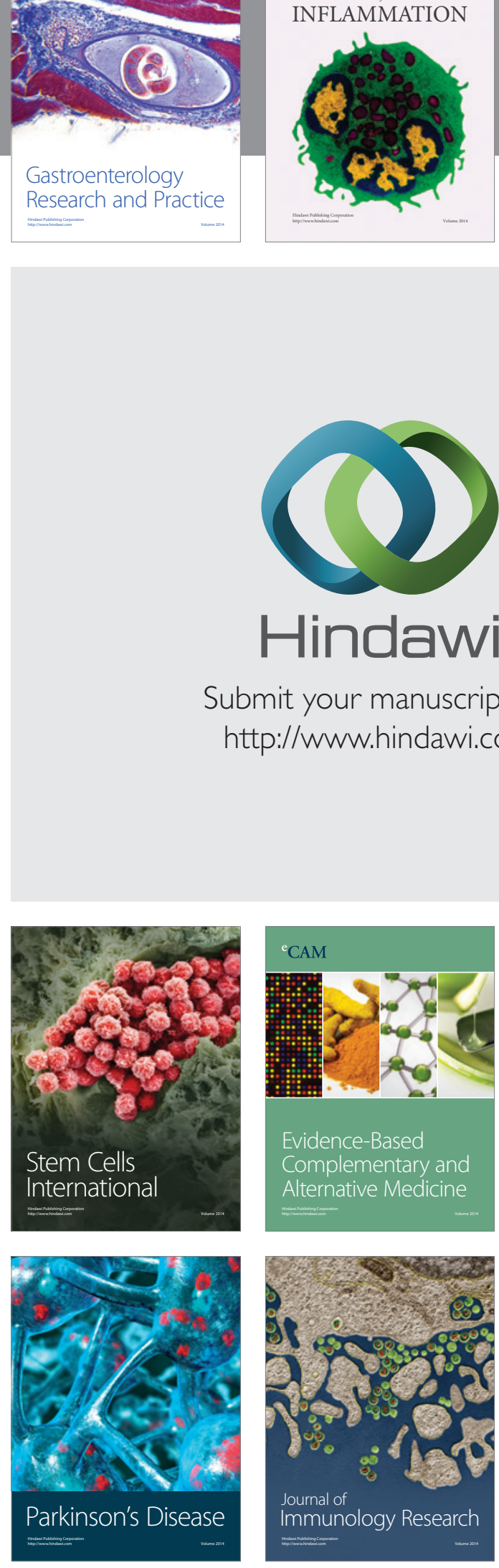

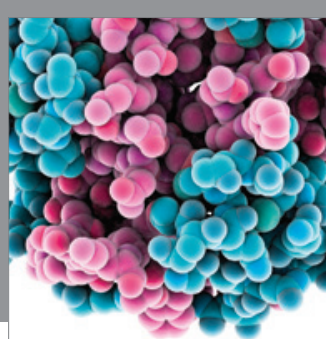

Diabetes Research
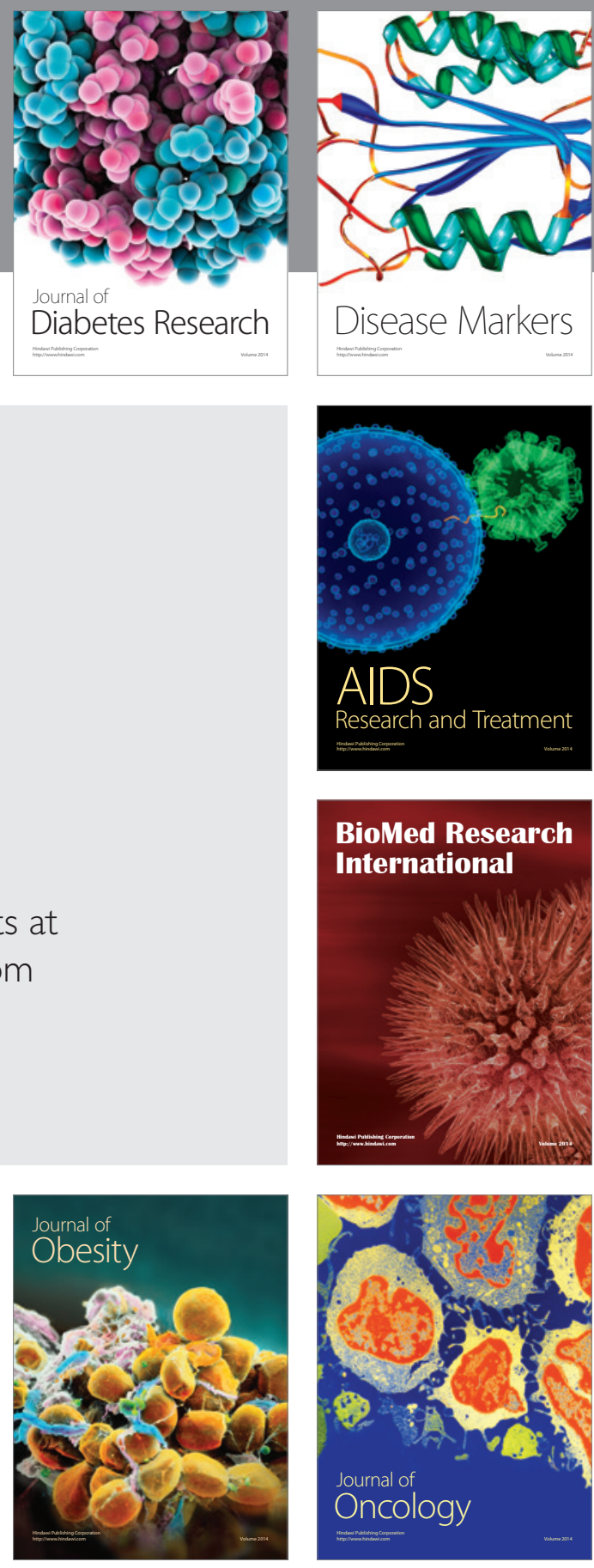

Disease Markers

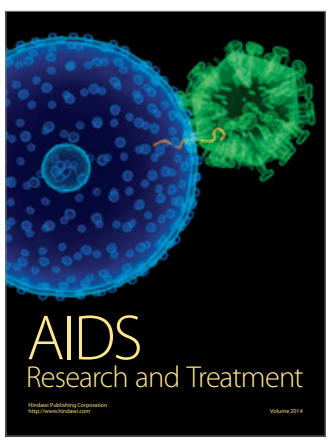

BioMed Research

International
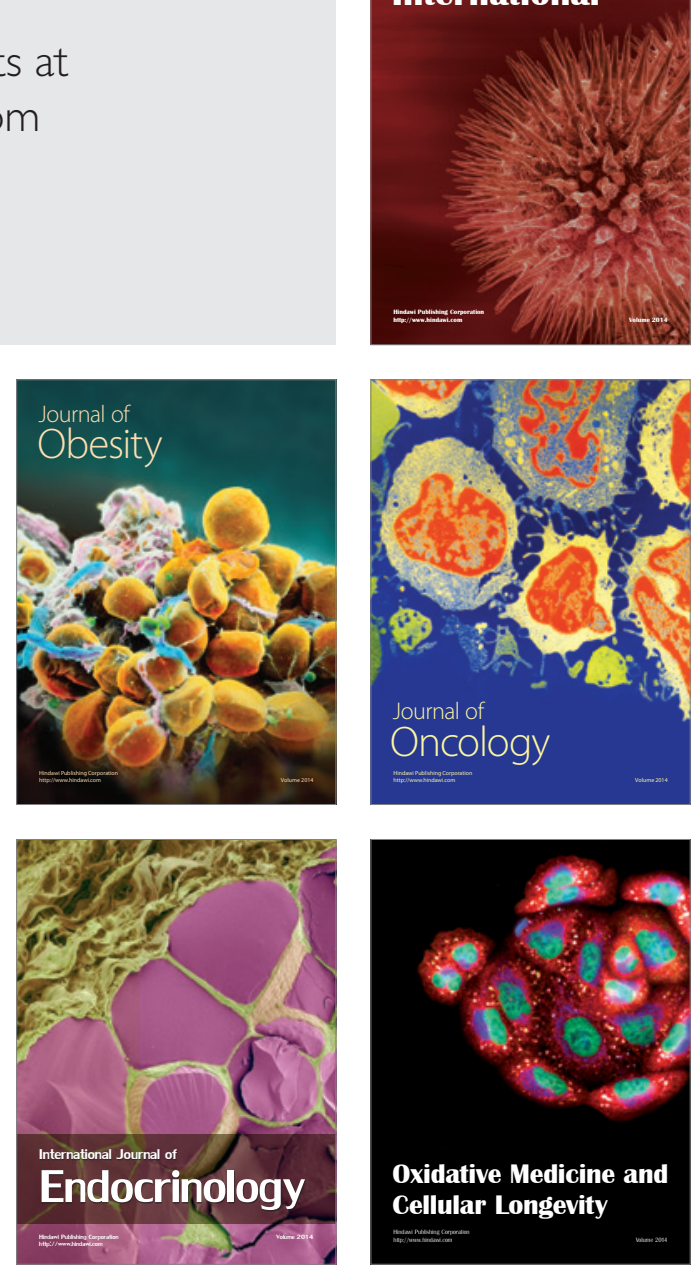